\title{
Precipitated silica as filler for polymer electrolyte based on poly(acrylonitrile)/sulfolane
}

\author{
Beata Kurc
}

Received: 28 January 2014 / Revised: 28 February 2014 / Accepted: 3 March 2014 / Published online: 21 March 2014

(C) The Author(s) 2014. This article is published with open access at Springerlink.com

\begin{abstract}
The aim of the present work was to perform a preliminary study of the physicochemical properties of hybrid organic-inorganic gel electrolytes for Li-ion batteries based on the PAN/TMS - poly(acrylonitrile)/sulfolane - polymeric matrix and surface-modified precipitated silicas. Modifications were done by means of the so-called dry method using silane U-511 3-methacryloxypropyltrimetoxysilane. Scanning electron microscopy (SEM), noninvasive back scattering method (NIBS), specific surface area (BET), the degree of modification of the silica fillers-Fourier-transform infrared spectroscopy (FT-IR), impedance analysis, and charging/ discharging were carried out. It is found that the silica fillers were homogeneously dispersed in the polymeric matrix, which enhanced conductivity and electrochemical stability of porous polymer electrolytes. Applicability of the prepared gel electrolytes for the Li-ion technology was estimated on the basis of specific conductivity measurements. It was shown that modification of the silica surface by the silane causes an increase in the gel-specific conductivity by about 2 orders of magnitude as compared to gel with unmodified silica.
\end{abstract}

\section{Introduction}

In recent years, much attention has been focused on the development of new inorganic-organic composite materials of prospective use in many areas [1-4]. Among the inorganic substances, silicon dioxide has become greatly important as an active filler of polymers [5-7]. Its importance follows from the possibility of controlling its physical properties (by method of

B. Kurc $(\bowtie)$

Faculty of Chemical Technology, Poznań University of Technology, 60965 Poznań, Poland

e-mail: beata.kurc@put.poznan.pl synthesis) $[8,9]$ and chemical properties (by surface modification) [10].

Gel-type electrolytes are regarded as a prospective alternative for traditional liquid electrolytes as far as lithium-ion ( $\mathrm{Li}-$ ion) batteries are considered. Gel electrolytes are obtained by placing some amount of liquid plasticizer and/or solvent in a polymer matrix. This idea was first demonstrated in 1975 by Feuillade and Perche [11] who studied the process of plasticizing a polymer (host matrix) with an aprotic solution containing an alkali metal salt. Since then, many different polymers were examined as possible gel matrices, including poly(vinylidene fluoride) (PVdF) [12], poly(acrylonitrile) (PAN) [13, 14], poly(methyl methacrylate) (PMMA) [15], and others.

The advantage of gel electrolytes over liquid electrolytes lies in the fact that the risk of leakages in the battery systems containing gels is reduced, since in principle, no free liquid is present in such systems. In addition to that, their specific conductivities are close to those exhibited by purely liquid electrolytes.

As was demonstrated in the works of Gozdz and Tarascon $[16,17]$, some gel electrolytes can have processing properties that enable successful application in large-scale production processes. One of the important findings of Gozdz and Tarascon was that the addition of highly dispersed silica to the PVdF-HFP matrix significantly enhances the solvent absorption ability, thus leading to a considerable increase in the measured conductivities. The positive effect of various ceramic particles (also $\mathrm{Al}_{2} \mathrm{O}_{3}, \mathrm{TiO}_{2}$, and others) on the conductivities of dry polymer electrolytes is also well-documented in the literature [18-23]. The key factors responsible for the performance of these ceramic additives are believed to be particle size and surface chemistry. Caillon-Caravanier et al. [24] found that the addition of unmodified silica provided better mechanical stability and improved the solvent absorption ability of membranes, thus enhancing the conductivities. In 
more recent works, Lee et al. studied the possibility of generating in situ fine silica particles dispersed in the PEO matrix [21] as well as of functionalization of silica surface with glycol chains [25]. Application of crosslinkable silicas modified with certain methacrylate monomers was also reported [26].

Currently, the most widely used separators in lithium-ion batteries are manufactured from polyolefins, predominantly polyethylene (PE) or polypropylene (PP), due to their suitable chemical stability, thickness, and mechanical strength [27]. However, several intrinsic factors such as low porosity, poor thermal stability, and insufficient electrolyte wettability and large difference of polarity between the highly polar liquid electrolyte and the nonpolar polyolefin separator lead to high cell resistance, low rate capability, and even internal short circuits of LIBs [28-30], which severely restricts the electrochemical performance of the LIBs, especially affects the safety performance of the LIBs. Therefore, the development of new separators possessing high porosity, good thermal stability, and high ionic conductivity is strongly demanded, especially in the thermal stability which seriously influences the practical application of LIBs.

In many studies, the fluorinated polymer poly(vinylidene fluoride) (PVdF) has been chosen as a polymer host due to its excellent thermal stability, outstanding mechanical property, and inertness to solvent [27,31]. Silicon dioxide, as the second component, was adopted for the interaction between the polar group of inorganic silicon dioxide sol surface and the interaction between the polar group, and fluorine atoms of PVdF molecular chain enhanced the adhesion properties between the fibers. Moreover, the addition of inorganic silicon dioxide could decrease the crystallinity of polymer, improves absorption for the electrolyte solution and ionic conductivity, thus improving the electrochemical performance of the separator. It also could highlight the advantage of inorganic materials, thus greatly improving the heat resistance of separators, which could enhance the safety of LIBs. Eun-Sun Choi et al. have made a research about $\mathrm{SiO}_{2} /$ poly(vinylidene fluoridehexafluoropropylene)-coated poly(ethylene terephthalate) nonwoven composite separator for a lithium-ion battery [27]. In their study, they have done much work on the influence of particle size, tunable porous structure of $\mathrm{SiO}_{2}$, on the performance of nonwoven composite separator. The separators prepared by relevant researchers provided substantial improvement in the thermal shrinkage, liquid electrolyte wettability, and electrochemical performance. Nevertheless, we noted that coating modification using varisized inorganic silicon dioxide particles was directly employed, which have some problems in controlling the stability and uniformity of $\mathrm{SiO}_{2}$ particle size during the processes of preparation and charging/discharging.

In some cases, hybrid membranes were prepared by sol-gel techniques [32-35]. The same approach was used to synthesize tailored organic-modified silica bearing a variety of functional groups, with a preference for hydrophilic fragments. The latter systems are devised to improve the proton conductivity and the water uptake of the resulting hybrid Nafion-based materials [36-39]. At present, the influence of the physicochemical properties of the inorganic fillers on the structure and the properties of the composite proton conducting polymer electrolytes is not well-understood and prompted us to investigate systematically composite Nafionbased membranes under different conditions [40].

A completely different approach is followed in the development of polymer electrolyte membranes consisting of a basic polymer such as polybenzimidazole impregnated with phosphoric acid [41]. These systems are designed to operate at high temperatures, above $150{ }^{\circ} \mathrm{C}$, which solves engineering problems arising from cell operation at lower temperatures [41]. Recent advances in polymer electrolytes for fuel cells include substitution of a proton-conducting ionic liquid (PCIL) for water as the proton transport medium [42-45], and the development of polyelectrolyte membranes capable of carrying $\mathrm{OH}-$ anions from the cathode to the anode which leads to systems able to operate effectively even in the absence of electrocatalysts based on platinum-group metals (PGM) $[46,47]$.

Thus, the motivation of this work was to examine the properties of $\mathrm{SiO}_{2}$ filler for composite polymer electrolytes. It may be expected that certain favorable properties of both unmodified and modified $\mathrm{SiO}_{2}$ will be reinforced and a synergic effect will be detected. This paper describes the synthesis and preliminary results for a new type of filler for PAN/TMS/ $\mathrm{LiPF}_{6}$-based composite gel electrolytes which is a precipitated silica oxide submicron powder.

\section{Experimental}

\section{Materials}

Silica dioxide was produced in the emulsion system using cyclohexane (analytical grade, made by POCh SA) as the organic phase, and sodium silicate and hydrochloric acid solutions used as precipitating agent. The nonionic surfactants from the group of oxyethylene alkylophenols, known as Rokafenol N3 and N6, were used as emulsifiers. The silica obtained in this way was modified with the proadhesive compound U-511 (3-methacryloxypropyltrimethoxysilane).

Graphite (G, SL-20, BET surface area $6.0 \mathrm{~m}^{2} \mathrm{~g}^{-1}$, Superior Graphite, USA), carbon black (CB, Fluka), poly(vinylidene fluoride) (PVdF, MW=180,000 Fluka), lithium foil (Aldrich, 0.75-mm thick), vinylene carbonate (VC, Aldrich), $N$-methyl2-pyrrolidinone (NMP, Fluka), dimethylformamide (DMF, Aldrich), lithium hexafluorophosphate $\left(\mathrm{LiPF}_{6}\right.$, Aldrich), and sulfolane (TMS, Fluka) were used as received. 
Measurements and apparatus

\section{Silicas}

Chemical composition of the silicas was analyzed using an Elementar model Vario EL Cube apparatus. During the measurements, the percentage contribution of N, C, H, and S was estimated. The degree of modification of the silica fillers was determined by FT-IR.

Specific surface areas of the selected silica powders were determined by $\mathrm{N}_{2}$ adsorption (BET method) using ASAP 2020 instrument (Micromeritics Instrument Co.). Moreover, the volume and size of pores of precipitated fillers applying BJH algorithm were examined. Samples were degassed at $120^{\circ} \mathrm{C}$ for $2 \mathrm{~h}$ prior to measurements.

The water wettability of the obtained fillers was measured in order to investigate the hydrophobic or hydrophilic characteristics of the surface. The measurements were carried out with the use of a K100 tensiometer (Krüss) equipped with appropriate software. The measurements were conducted over an equal time period, until a stable sample mass value was obtained (approx. $10 \mathrm{~min}$; the mass was $0.4 \mathrm{~g}$ ).

Particle size distributions of silica suspensions were characterized in isopropanol and in the monomer with a Zetasizer Nano ZS (Malvern Instruments Ltd.). Size of silica particles as well as particle size distribution (PSD) were performed employing the technique of noninvasive back scattering method (NIBS) with a constant $173^{\circ}$ scattering angle, at $25 \pm$ $0.1^{\circ} \mathrm{C}$. The obtained particle size is a volume-weighted mean diameter, which is also called " $z$-average diameter." Particle size was measured for each composition six times; the final result assumed a mean value.

The morphology and microstructure of silica particles were characterized with low-voltage SEM (EVO40, Zeiss).

\section{Electrodes and electrolytes}

Polymer electrolytes (PEs) were prepared by the casting technique. First, the polymer (PAN) was swollen in DMF at $50^{\circ} \mathrm{C}$. After $24 \mathrm{~h}$, the polymer solution was mixed with the electrolyte (1 M LiPF 6 in TMS - sulfolane was the environment to dissolve the salt: $\mathrm{LiPF}_{6}$ ) clean and with the addition of $3 \mathrm{wt} . \%$ unmodified and modified $\mathrm{SiO}_{2}$. The viscous solution of the polymer in a mixture of the solvent (DMF) and sulfolane was cast onto a glass plate. After weighing, the plate was transferred into a desiccator, where the volatile solvent (DMF) was slowly evaporated under a stream of dry argon, first at room temperature. The composition of the system was monitored by weight. When the weight of nonvolatile components was achieved, this suggested that all amount of DMF was removed. After evaporation of the volatile component, the plate with the polymer electrolyte foil was weighed again and the composition was determined from the mass balance (with an accuracy of $10^{-4} \mathrm{~g}$ ). The resulting gel-type polymer electrolytes were self-standing membranes, homogeneous, and transparent. Polymer electrolytes were soaked with a drop of vinylene carbonate (VC, 7-8 \%) before cells assembling. Tested anodes were prepared on a copper foil (Hohsen, Japan) by the casting technique, from a slurry of graphite $(G)$, carbon black (CB), and PVdF in NMP. The ratio of components was $\mathrm{G}: \mathrm{CB}: \mathrm{PVdF}=85: 5: 10$ (by weight). After solvent (NMP) evaporation at $120{ }^{\circ} \mathrm{C}$ in vacuum, a layer of the carbon electrode, containing the active material $(\mathrm{G})$, the electronic conductor $(\mathrm{CB})$, and the binder (PVdF), was formed. Typically, mass of electrodes was as follows: Li: ca. $45 \mathrm{mg}$ $\left(0.785 \mathrm{~cm}^{2}\right)$ and anode: $3.0-4.0 \mathrm{mg}$.

Electrochemical properties of the cells were characterized using electrochemical impedance spectroscopy (EIS) and galvanostatic charging/discharging tests. The $\mathrm{Li} /$ electrolyte/Li and the $\mathrm{Li} /$ electrolyte/G cells were assembled in a dry argon atmosphere in a glove box. Two lithium foils or lithium foil and a graphite electrode were separated by polymer electrolyte, placed in an adapted Swagelok ${ }^{\circledR}$ connecting tube. Geometrical surface area of $\mathrm{Li}$ and graphite electrodes was $1 \mathrm{~cm}^{2}$. Interface resistance at the electrode/polymer electrolyte interface was measured with an ac impedance analyzer (AtlasSollich System, Poland). The impedance spectra were recorded from $0.01 \mathrm{~Hz}$ to $10 \mathrm{kHz}$ at the amplitude of $10 \mathrm{mV}$.

Conductivity of liquid electrolytes was measured in a twoelectrode $(\mathrm{Pt})$ thermostated conductometric glass cell with the constant of $4.80 \mathrm{~cm}^{-1}$. The corresponding conductivity data for polymer electrolytes, sandwiched between two gold blocking electrodes, were measured in the Swagelok ${ }^{\circledR}$ connecting tube, placed in an air thermostat. During conductivity measurements of both the liquid and polymer electrolytes, impedance were recorded between $1 \mathrm{~Hz}$ and $10 \mathrm{kHz}$ at the amplitude of $10 \mathrm{mV}$. The cycling tests on the Li/ electrolyte/G cells were performed between 0.001 and $2.5 \mathrm{~V}$ at the current rate of $\mathrm{C} / 10$. After electrochemical measurements, cells were disassembled, graphite electrodes washed with DMC and dried in vacuum at room temperature. The morphology of polymer electrolyte was observed with a scanning electron microscopy (SEM, Tescan Vega 5153).

\section{Preparation of precipitated silica}

Two types of emulsions were prepared. The first one labeled as E2 and referred to as acidic was composed of the organic phase (cyclohexane POCh SA) and a $5 \%$ solution of hydrochloric acid (POCh SA). It also included nonylphenylpolyoxyethyleneglycol ethers (NP3 and NP6, PCC Rokita SA). The second emulsion labeled E1 was referred to as the basic one. It contained a fixed volume of a $20 \%$ solution of sodium silicate (Vitrosilicon SA) into which cyclohexane and emulsifiers (NP3 and NP6) were introduced in appropriate amounts. The emulsions were obtained by 
dissolving weighted portions of nonionic surfactants in cyclohexane. The mixture obtained was applied in small doses into the water phase being a water solution of sodium silicate for E1 and a water solution of hydrochloric acid for E2. The E2 emulsion was homogenized in the next step for $20 \mathrm{~min}$ at the rate of 8,800 rpm and placed in a reactor (QVF Miniplant Pilot-Tec) of $10 \mathrm{dm}^{3}$ in capacity (under continuous stirring at the rate of $760 \mathrm{rpm}$ ). Then, E1 was homogenized at the rate of $8,800 \mathrm{rpm}$ for $20 \mathrm{~min}$. After this stage, E1 was introduced in doses into $\mathrm{E} 2$ at the rate of $20 \mathrm{~cm}^{3} \mathrm{~min}^{-1}$ using a peristaltic pump. As a result of dispergation a white sediment of silica appeared, which was later destabilized at $80{ }^{\circ} \mathrm{C}$ in order to separate the organic phase. The sample was filtered of under reduced pressure. The filtration residue obtained was washed a few times with hot water and then with methanol in order to remove possible residues of surfactants. The last phase of the process was the removal of humidity from the silica by spray drying in a GeoNiro A/S.

Figure 1 presents a possible mechanism of silica precipitation from a system of two emulsions followed by destabilization in order to separate the silica of spherical shape particles and recovery of the hydrocarbon used (for example cyclohexane).

\section{Modification of silica particles}

The modification of silica surface was performed in a reactor containing $20 \mathrm{~g}$ of silica support and a solution of the modifying compound. The solution contained 3methacryloxypropyltrimethoxysilane (U-511) in the amount of 5, 10, 20 weight parts by mass (wt.\%) and a certain amount of the solvent of water and methanol mixed at the 1:4 $(\mathrm{v} / \mathrm{v})$ ratio. The modification was performed in a mixer according to the earlier described procedure [48].

\section{Results}

At the first stage of the study, the spherical silica was precipitated and subjected to dispersion analysis. The particle size distribution (Fig. 2a) revealed a single band corresponding to the particles of diameters covering the range 164-295 nm, with the maximum volume of $37.2 \%$ corresponding to the particles of $220 \mathrm{~nm}$ in diameter. The SEM of the silica (Fig. 3a) confirmed the above result as the sample showed high uniformity and a few agglomerates. The polydispersity index of this silica material was 0.250 .

The surface modification caused a shift in the particle size range of the filler. Respectively, for 5 wt.\% (Fig. 2b): 396$825 \mathrm{~nm}, 10$ wt.\% (Fig. 2c): $296-725 \mathrm{~nm}$, and 20 wt.\% (Fig. 2d): $342-712 \mathrm{~nm}$. The polydispersity values are 0.280 0.310 . The mean diameter of the silica particles and value of polydispersity means that the samples are rather homogeneous. The state of dispersion is illustrated in the SEM image (Fig. 3b-d).

The introduction of alkoxysilanes in small amounts of 5, 10 , and $20 \mathrm{wt} . \%$ does not cause significant changes in the particle size distribution. The average particle diameter is changed as follows: 5 wt.\%: $615 \mathrm{~nm}, 10$ wt.\%: $515 \mathrm{~nm}$, 20 wt.\%: $531 \mathrm{~nm}$.

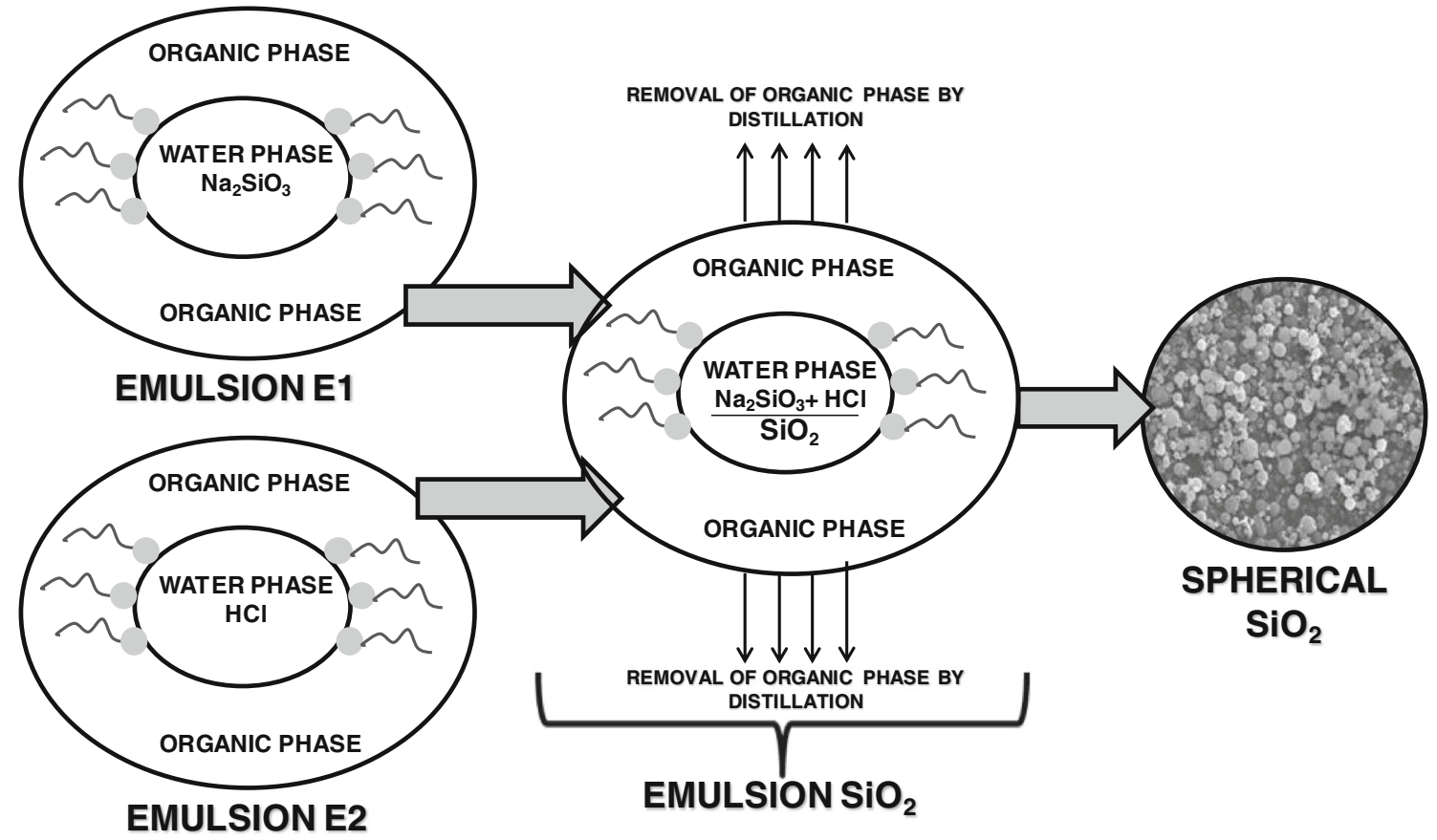

Fig. 1 Mechanism of the silica synthesis by the method of precipitation in the emulsion system 

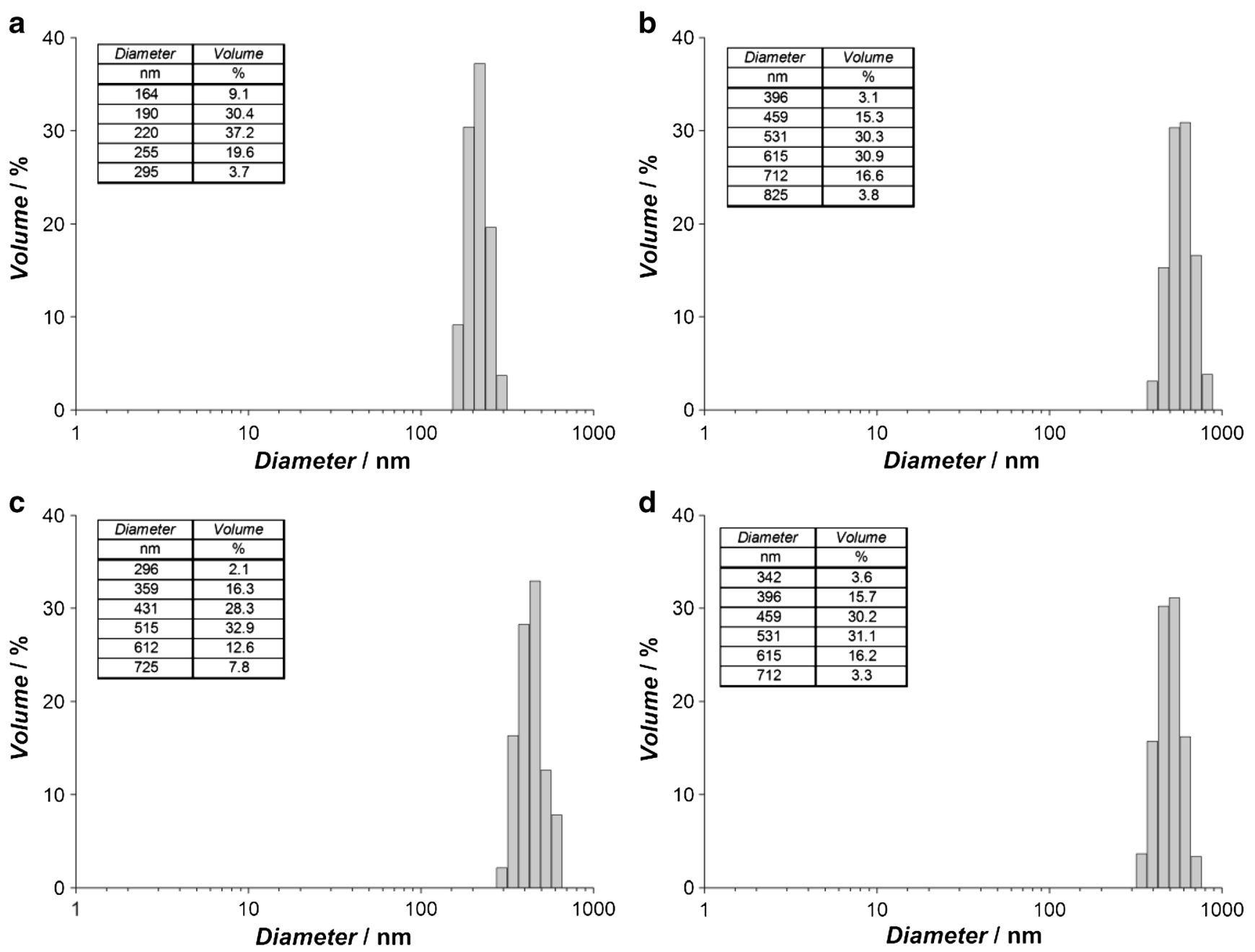

Fig. 2 PSD and of silica unmodified a) and modified with 5 b), $10 \mathbf{c}$ ), and 20 d) wt.\% of U-511 silane

The FT-IR spectroscopic analysis has provided information on the $\mathrm{SiO}_{2} /$ modifier interactions. The unmodified silica (sample $\mathrm{SiO}_{2}$ ) has its functional groupssilanols almost totally blocked $\left(3,748 \mathrm{~cm}^{-1}\right.$; Fig. 4). It is explained by a strong interaction of the emulsifiers with the precipitating silica and their partial grafting into the surface structure of the silica.

The mechanism of this interaction may be based on the chemical reaction of the silanol group present on the silica surface with the hydroxyl group or on the formation of hydrogen bonds between the hydroxyl groups on the $\mathrm{SiO}_{2}$ surface and those from the emulsifier. Moreover, in the spectrum of the unmodified sample, the characteristic broad band assigned to the physically bound water $\left(3,200-3,600 \mathrm{~cm}^{-1}\right)$ has low intensity, while the band assigned to the stretching vibrations of $=\mathrm{CH}\left(2,965-2,850 \mathrm{~cm}^{-1}\right)$ is relatively well pronounced. After modification with U-511, the intensity of the band assigned to the silanol groups at $3,660 \mathrm{~cm}^{-1}$ decreased, while that of the band assigned to the $\sigma \mathrm{C}-\mathrm{H}$ bond, at $2,965-2,850 \mathrm{~cm}^{-1}$, increased. These changes prove the chemical character of the silica surface modification with 3- methacryloxypropyltrimethoxysilane. The presence of this band confirms strong interactions of the emulsifier used with the surface of $\mathrm{SiO}_{2}$. Modification with the alkoxysilane studied led to similar changes in the intensity of the spectroscopic bands.

Hydrophilic nanoparticles and hydrophobic polymers are not compatible in nature, which will result in poor interfacial interaction $[49,50]$. Above all, it is necessary to modify the surface of silica (nano)particles. Surface modification techniques for preventing nanoparticles from aggregation became important in the applications of nanoparticles [49]. In general, there are two basic routes to surface modification of inorganic fillers: physical adsorption of polymer and covalently attachment by chemical reaction. The resultant bonding is often a mixture of secondary and chemical bonds. Physical treatment (through covering the filler with a low molecular weight surfactant or a high molecular weight polymer) usually results in secondary forces (such as van der Waals, hydrogen and electrostatic forces) between particles and the modifier [51]. The covalent-bond polymer can usually overcome drawbacks of the prepared by physical adsorption, such as adhesive force 
Fig. 3 SEM image of silica unmodified a) and modified with 5 b), 10 c), and 20 d) wt. $\%$ of U-511 silane
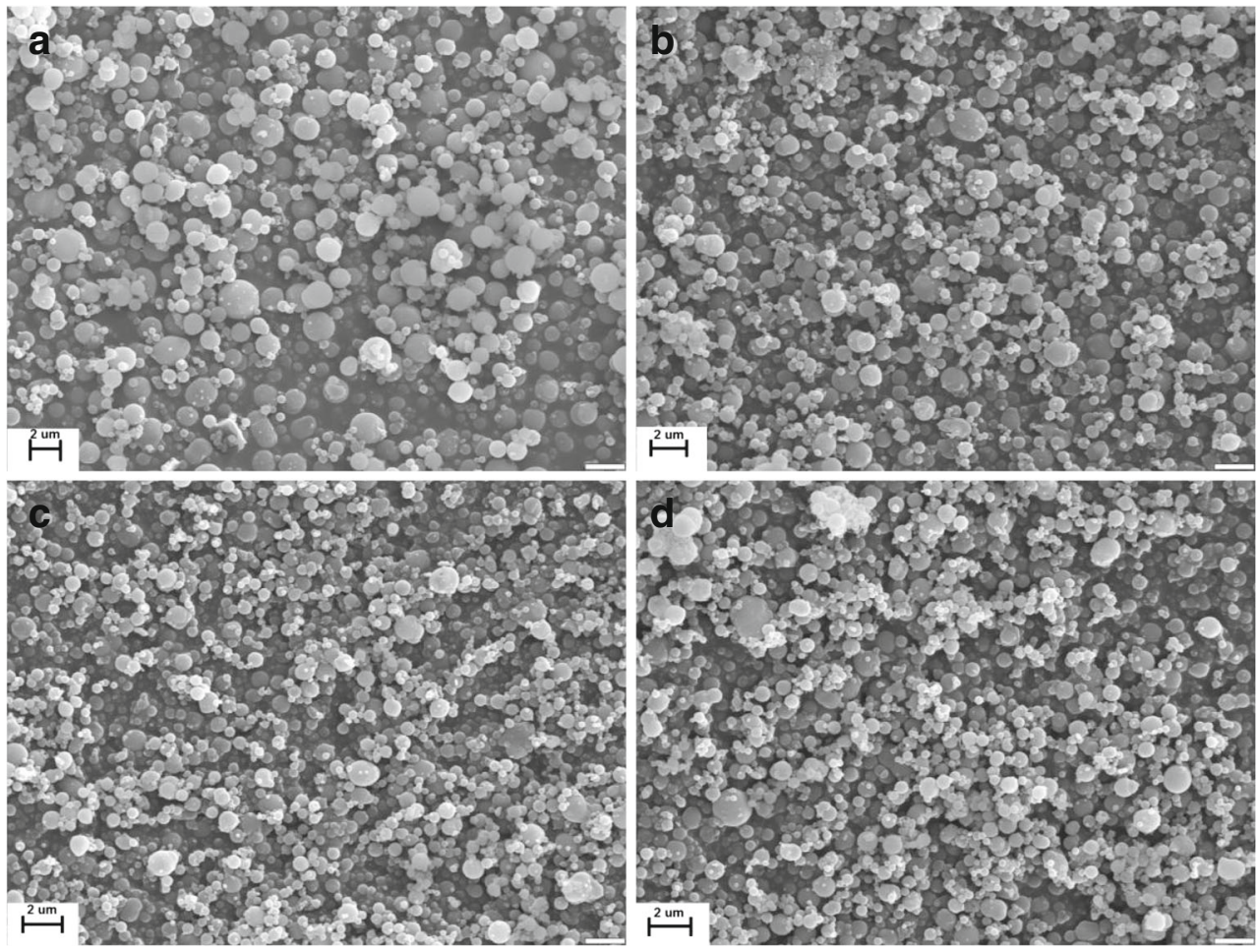

and a low grafting densities [52], because the covalent attachment modifier avoids its desorption from the particles surface.

Surface modification of silica fillers resulted in a distinct shift towards a more hydrophobic with increasing the quantity of U-511. Figure 5 shows wettability profiles with water of both unmodified and modified silicas. Character of the wetting curve of modified silica confirms the change in the surface character of the support from hydrophilic to partially hydrophobic.

For the silica samples modified with U-511, the results of the wettability test indicated high chemical affinity and the possibility of interaction with water molecules through

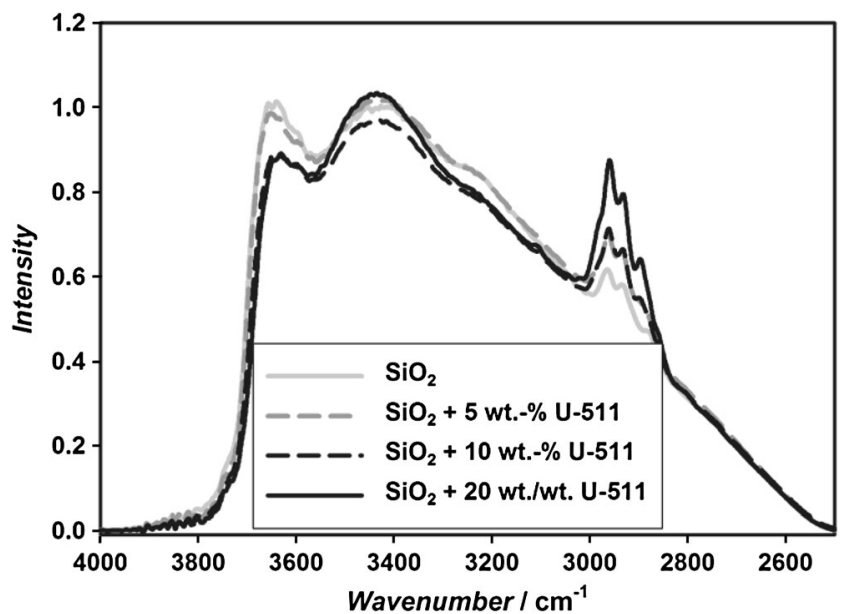

Fig. 4 FT-IR spectra of silica unmodified and modified with 5, 10, and 20 wt. $\%$ of U-511 silane hydrogen bonds. Furthermore, the increased hydrophobicity corresponds to an increased amount of the emerging functional groups derived from the silane and decreasing a surface area resulting from the saturation of the active filler.

Furthermore, $\mathrm{N}_{2}$ sorption experiments were carried out to determine the structural properties of the silica fillers (Table 1). The surface area $\left(A_{\mathrm{BET}}\right)$ of unmodified silica $\mathrm{SiO}_{2}$ is much larger $\left(48 \mathrm{~m}^{2} \mathrm{~g}^{-1}\right)$ than for modified silicas $\left(15-37 \mathrm{~m}^{2} \mathrm{~g}^{-1}\right)$. The pore volume $\left(V_{\mathrm{p}}\right)$ of the unmodified silica is greater than the silane-grafted silicas. However, the average pore diameter $\left(S_{\mathrm{p}}\right)$ of modified silica is slightly greater than the unmodified sample, which can be explained by the migration of modifier into the pores.

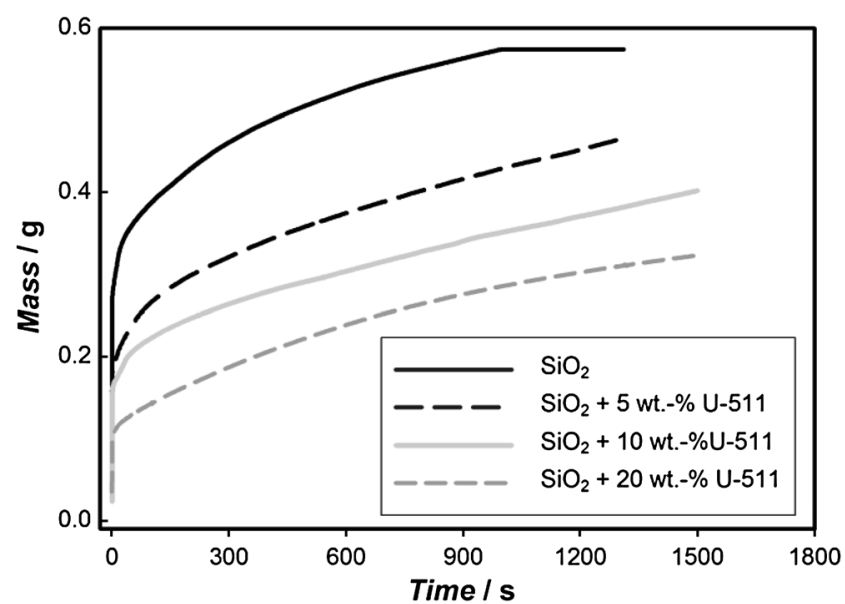

Fig. 5 Wettability of silica unmodified and modified with 5, 10, and 20 wt. $\%$ of U-511 silane 
Table 1 Parameters of porous structure of unmodified and silane-grafted silicas

\begin{tabular}{lllll}
\hline Acronym filler & Silica fillers & $A_{\mathrm{BET}} / \mathrm{m}^{2} \mathrm{~g}^{-1}$ & $V_{\mathrm{p}} / \mathrm{cm}^{3} \mathrm{~g}^{-1}$ & $S_{\mathrm{p}} / \mathrm{nm}$ \\
\hline $\mathrm{S}$ & $\mathrm{SiO}_{2}$ & 48 & 0.59 & 12.43 \\
SM5 & $\mathrm{SiO}_{2}+5$ wt.\% U-511 & 37 & 0.42 & 13.104 \\
SM10 & $\mathrm{SiO}_{2}+10$ wt.\% U-511 & 27 & 0.20 & 18.89 \\
SM20 & $\mathrm{SiO}_{2}+20$ wt.\% U-511 & 15 & 0.15 & 18.1 \\
\hline
\end{tabular}

The products were also subjected to elemental analysis to get percentage contents of $\mathrm{C}$ and $\mathrm{H}$ (Table 2). The contents of carbon and hydrogen increase in proportion to increasing U-511 concentration in the solution used for modification.

Modification of $\mathrm{SiO}_{2}$ causes change in the chemical and physical properties, mainly hydrophilic-hydrophobic properties, as well as the introduction of the surface of the silicaspecific functional groups that can easily react with the centers in which these systems will be used. To determine the hydrophilic-hydrophobic surface properties of silica particles before and after modification, the parameters in the water wettability were measured.

Studies have shown that the nature of the wetting profile depends mainly on the amount of modifier used. The increase in hydrophobicity of the surface of $\mathrm{SiO}_{2}$, especially when using larger quantities of modifier, reduces the rate of wetting.

The only noticeable difference in the change between the applied silicas can be seen in the measurement of the surface area. It should be noted that in the case of $A_{\mathrm{BET}}$, precipitated silica corresponds mainly to the external surface, such as silica is almost perfectly spherical particles.

Modification of the silica surface is a complex process dependent on many parameters. The type of solvent and modifying substance, its quantity in the solution, the $\mathrm{pH}$ of the environment, modification time, and additives that catalyze the modification process is important [52]. By the choice of suitable polyfunctional compounds containing not only groups capable of interacting with the surface of silica, but also a group of the chemical affinity with the functional groups of organic compounds, adsorption capacity of the silica carrier can be corrected.

Alkoxysilanes can bind chemically with the silica surface in the presence of water only. Thus, the silane molecules must be hydrolyzed before the reaction with the mineral surface of

Table 2 Elemental content of carbon and hydrogen of tested silica fillers the substrate. The mechanism of this process is shown in Scheme 1.

Figure 6 shows the comparison of morphology between membranes without silica fillers and containing modified silica with 5 wt.\% U-511. In the case of adding silica to the polymer electrolyte, $\mathrm{SiO}_{2}$ aggregates can be seen in the holes of membranes. There are no $\mathrm{SiO}_{2}$ aggregates to be seen on the upper surface, indicating that the added $\mathrm{SiO}_{2}$ is, therefore, concentrated in the phase-separated water droplets and filled in the holes when porous membrane is formed. Moreover, you can see a clear difference between the electrolytes. The addition of only $5 \%$ of the modified silica allows detecting the presence of spherical particles.

Figure 7 shows the temperature dependence of ionic conductivity of pristine and composite polymer electrolytes. The gel electrolytes based on modified silica composite membranes present higher ionic conductivities than that based on pristine membrane, indicating that silica composite improved ionic conductivity of gel electrolyte based on porous membrane.

The lowest value of the ionic conductivity at $25^{\circ} \mathrm{C}$ shows a pure electrolyte (EN) - it is $1 \times 10^{-4} \mathrm{~S} \mathrm{~cm}^{-1}$. The addition of unmodified silica (ES) caused an increase in conductivity by orders of magnitude $-2.8 \times 10^{-3} \mathrm{~S} \mathrm{~cm}^{-1}$. Modification of $\mathrm{SiO}_{2}$ with selected alkoxysilane $\mathrm{U}-511$ results in a significant increase of conductivity. The maximum value observed with the addition of filler to polymer electrolyte modified $5 \mathrm{wt} \%$ U-511 (ESM5) $-4.9 \times 10^{-2} \mathrm{~S} \mathrm{~cm}^{-1}$. Moreover, increasing the amount of silane resulted in a decrease of conductivity: for 10 wt.\% U-511 (ESM10), $3 \times 10^{-2} \mathrm{~S} \mathrm{~cm}^{-1}$ and for $20 \mathrm{wt} \%$ U-511 (ESM20), the value was much lower: $5.9 \times 10^{-3} \mathrm{~S} \mathrm{~cm}^{-1}$ (Fig. 8).

What is interesting is that the higher conductivity values were obtained for membranes containing bigger diameter and not smaller of the $\mathrm{SiO}_{2}$ particles. Surface modification resulted in an increase average diameter composite particles introduced into the polymer electrolyte. For a pure $\mathrm{SiO}_{2}$, average particle diameter was about $220 \mathrm{~nm}$, and for modified composites it increased to SM5, $615 \mathrm{~nm}$; SM10, $515 \mathrm{~nm}$; and SM20, $531 \mathrm{~nm}$. This may mean that $\mathrm{SiO}_{2}$ of greater size comprises a greater number of active groups resulting from the modification. The highest ionic conductivity value at $25{ }^{\circ} \mathrm{C}$ was measured for the membrane containing microsize $\mathrm{SiO}_{2}$ with methacryloxy groups on the surface (5 wt.\%) (4.9× $10^{-2} \mathrm{~S} \mathrm{~cm}^{-1}$ ) (Fig. 8) [53]. 
Scheme 1 Proposed mechanism of silane compounds that bind with surface silanol on silica
Hydrolysis of alkoxysilane

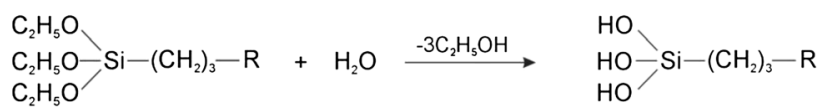

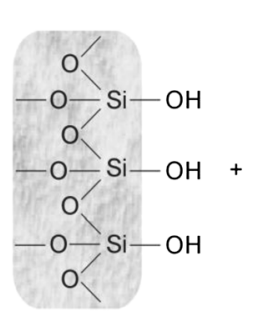

Condensation of alkoxysilane with silica surface

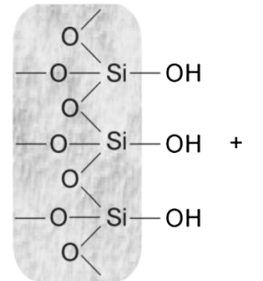

$$
\underset{\mathrm{HO}}{\mathrm{HO}}-\mathrm{Si}-\left(\mathrm{CH}_{2}\right)_{3}-\mathrm{R} \stackrel{-}{\longrightarrow}
$$$$
\text { O }
$$

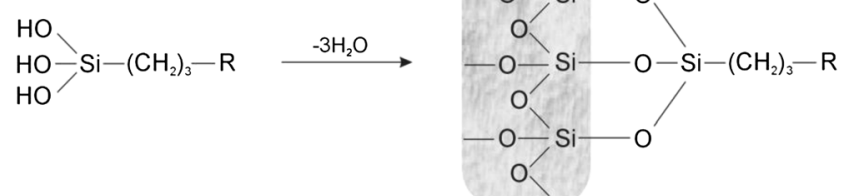

The specific conductivity of a number of representative ionic liquids is shown in [54]. As can be seen, the room
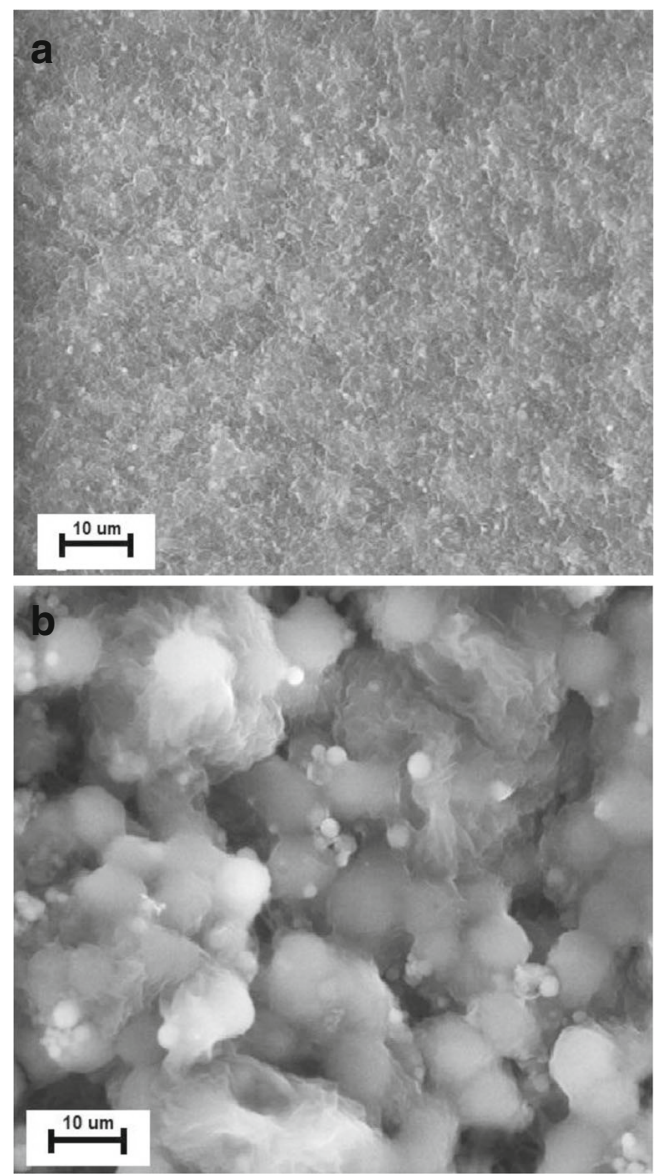

Fig. 6 Scanning electron microscope images of electrolytes membrane: a) ES and b) ESM5 temperature conductivities, $\sigma$, are within a broad range of $0.1-18 \mathrm{mS} \mathrm{cm}{ }^{-1}$. Generally, conductivity of the order of $10 \mathrm{mS} \mathrm{cm}{ }^{-1}$ is typical of ionic liquids based on [EtMeIm] ${ }^{+}$. On the other hand, ionic liquids based on tetraalkylammonium, pyrrolidinium, piperidinium, and pyridinium cations are characterized by considerably lower conductivities, in the range between 0.1 and $5 \mathrm{mS} \mathrm{cm}^{-1}$. Even the highest room temperature ionic liquid conductivity is much lower in comparison to conventional aqueous electrolyte solutions applied in electrochemistry. For example, the specific conductivity of aqueous $\mathrm{KOH}$ (29.4 wt.\%) solution, applied in alkaline batteries, is $540 \mathrm{mS} \mathrm{cm}^{-1}$. The electrolyte applied in lead-acid batteries, 30 wt. \% aqueous $\mathrm{H}_{2} \mathrm{SO}_{4}$, shows a conductivity at the level of ca. $730 \mathrm{mS} \mathrm{cm}^{-1}$. However, nonaqueous solutions show 1 order of magnitude lower conductivity. One of the most conductive $\mathrm{Et}_{4} \mathrm{NBF}_{4}$ solutions, in

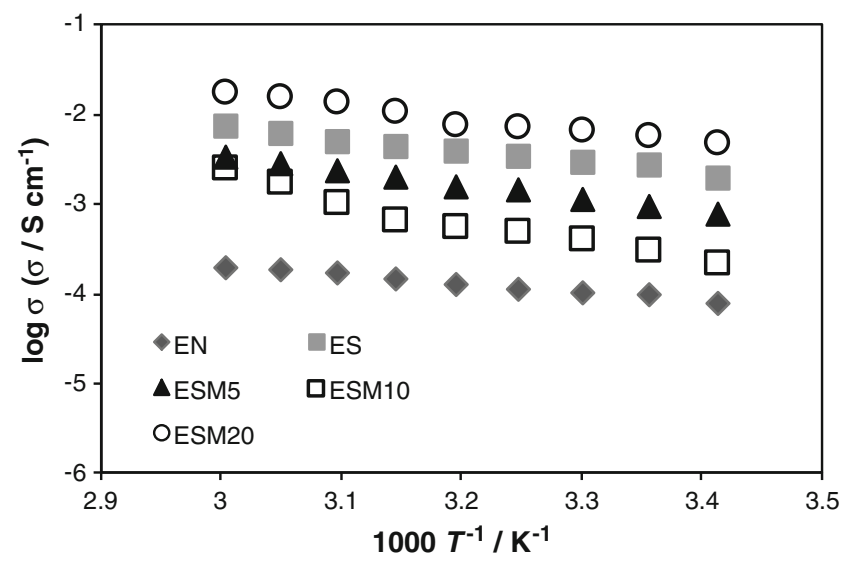

Fig. 7 Temperature dependencies of ionic conductivities determined of the gel electrolytes with various fillers presented as Arrhenius plots 

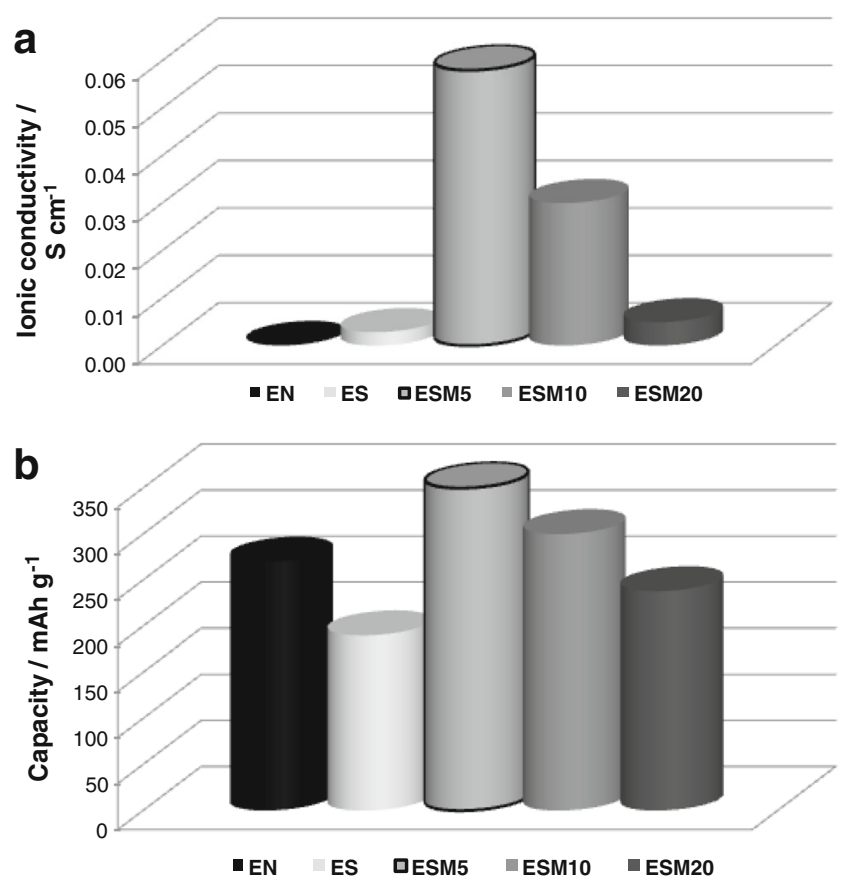

Fig. 8 Ionic conductivity of the dry polymer electrolytes at $25{ }^{\circ} \mathrm{C}$ a); charging capacity of the cell: G|electrolyte $\mid \mathrm{Li}(\mathrm{C} / 5)$ - b)

acetonitrile, for application in double-layer capacitors is characterized by $\sigma=60 \mathrm{mS} \mathrm{cm}^{-1}$. Lithium ion containing solutions, for use in lithium-ion batteries, show a conductivity at the level of $10 \mathrm{mS} \mathrm{cm}^{-1}$, similar to that characteristic for some ionic liquids. The conductivity of a solution of $\mathrm{LiPF}_{6}$ $\left(1 \mathrm{~mol} \mathrm{dm}^{-3}\right)$ in a mixture of ethylene carbonate with 1,2dimethoxyethane $(\mathrm{EC}+\mathrm{DME})$ is $16.6 \mathrm{mS} \mathrm{cm}^{-1}$. A dilution of neat ionic liquids with solvents (molecular liquids) also brings about an increase in conductivity. For example, the specific conductivity of neat [EtMeIm] $\left[\mathrm{BF}_{4}\right]$ is $14 \mathrm{mS} \mathrm{cm}$, while its $2 \mathrm{~mol} \mathrm{dm}^{-3}$ solution in acetonitrile shows a conductivity of $47 \mathrm{mS} \mathrm{cm}{ }^{-1}$. This is not unexpected, as an ionic liquid + molecular liquid mixture is a solution of a salt in a solvent, and therefore, ions are separated by solvent neutral molecules. However, at higher salt concentrations, all solvent molecules are involved in the ions primary salvation shell, and the resulting system, called "solvent in salt solution," may show properties rather characteristic for ionic liquids than that typical of classical solutions. In such a case, the conductivity increases with the increasing amount of the salt, goes through a maximum, and decreases with a further increase of the salt concentration [54].

Figure 9 shows the charging/discharging curves for the G|electrolyte|Li cell assembled from the graphite anode. It can be seen that such an electrode capacity was stable during the cycles. The current rate $\mathrm{C} / 5$ was optimal for all electrolytes.

The charging and discharging capacity of the graphite anode with electrolytes containing modified silica was between $238 \mathrm{mAh} \mathrm{g}^{-1}$ (ESM20), $300 \mathrm{mAh} \mathrm{g}^{-1}$ (ESM10), and
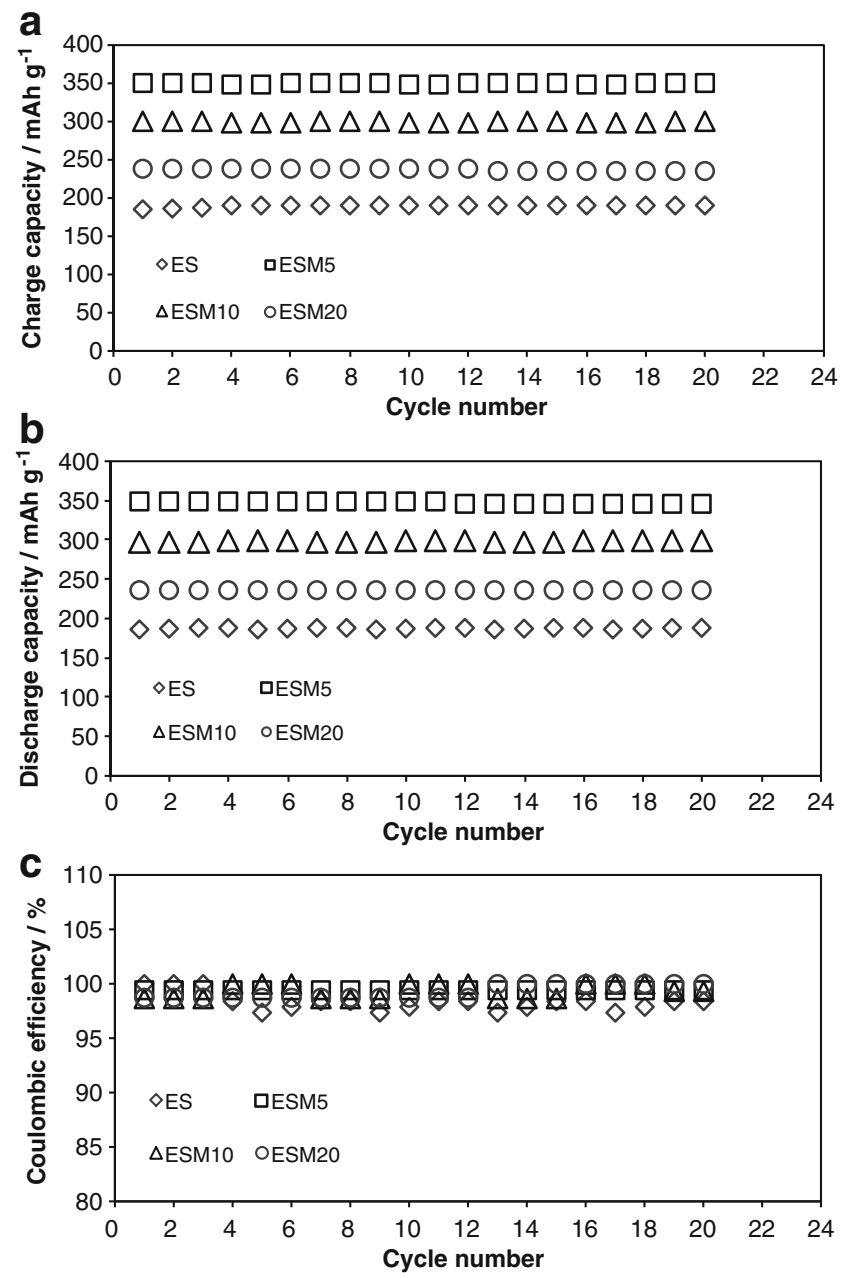

Fig. 9 Charge capacity a), discharge capacity b), and coulombic efficiency c) of the cell: G|electrolyte $\mid \mathrm{Li}(\mathrm{C} / 5)$

$350 \mathrm{mAh} \mathrm{g}^{-1}$ (ESM5). The resulting capacity for graphite electrode can be applied to the conductivity. The highest capacity and conductivity belong to the electrolyte which contains $5 \mathrm{wt} . \%$ of 3-methacryloxypropyltrimethoxysilane (U-511). The charge/discharge efficiency of the cell: G|electrolyte|Li (C/5) was ca. $98 \%$ after 20 cycles.

The number of possible charging/discharging cycles is one of the most important factors characterizing any energy storage device. Lithium-ion batteries working with classical electrolytes show the life cycle of ca. 500-1,000. In the case of studies on ionic liquid electrolytes, usually $10-100$ cycles are reported. Also, the capacity loss may be higher when ionic liquids are used as electrolytes [55].

Graphite is usually used as an anode for the Li-ion secondary batteries with different types of electrolytes, including ionic liquids. In the case of the primary battery, metallic lithium may be used due to its high specific energy. The anion $\left[\mathrm{X}^{-}\right]$of the ionic liquid $\left[\mathrm{Li}^{+}\right]\left[\mathrm{A}^{+}\right]\left[\mathrm{X}^{-}\right]$is important from the point of view of the graphite electrode performance. The bis(trifluoromethanesulfonyl)imide anion seems to be the 
most popular component of ionic liquids applied as electrolytes in Li-ion batteries. However, the graphite anode requires the presence of a SEI forming additive. It has been found that replacing the bis(trifluoromethanesulfonyl)imide anion $\left(\left[\mathrm{N}\left(\mathrm{CF}_{3} \mathrm{SO}_{2}\right)_{2}{ }^{-}\right]\right.$or $\left.\left[\mathrm{NTf}_{2}{ }^{-}\right]\right)$by bis(fluorosulfonyl)imide anion $\left(\left[\mathrm{N}\left(\mathrm{F}_{2} \mathrm{SO}_{2}\right)_{2}{ }^{-}\right]\right.$or $\left.\left[\mathrm{Nf}_{2}{ }^{-}\right]\right)$may prevent the irreversible $\mathrm{Li}+$ intercalation into graphite [56]. The influence of the anion $\left(\left[\mathrm{NTf}_{2}{ }^{-}\right]\right.$or $\left[\mathrm{Nf}_{2}{ }^{-}\right]$) on cycling performance of the $\mathrm{Li} / \mathrm{LiCoO}_{2}$ cell filled with the $\left[\mathrm{MePrPip}^{+}\right]$-based ionic liquid was examined [57]. The initial capacity of the cell containing $\left[\mathrm{MePrPip}{ }^{+}\right]\left[\mathrm{NTf}_{2}{ }^{-}\right]$was slightly lower than that containing $\left[\mathrm{MePrPip}{ }^{+}\right]\left[\mathrm{Nf}_{2}{ }^{-}\right]$. Capacity retention at the next cycle (at $0.1 \mathrm{C}$ rate) was $90 \%$ in the case of the $\left[\mathrm{MePrPip}{ }^{+}\right]\left[\mathrm{Nf}_{2}{ }^{-}\right]$containing cell, while the cell containing $\left[\mathrm{MePrPip}{ }^{+}\right]\left[\mathrm{Nf}_{2}{ }^{-}\right]$ showed only $50 \%$ efficiency [57]. The influence of the $\left[\mathrm{Nf}_{2}{ }^{-}\right]$ anion on the reversible anode capacity has also been shown in the case of a number of other ILs [58, 59]. High lithiation capacity and good safety characteristics of amorphous silicon make it a good candidate for the anode material in Li-ion batteries. A thin film Si anode in $\left[\mathrm{Li}^{+}\right]\left[\mathrm{MePrPip}{ }^{+}\right]\left[\mathrm{Nf}_{2}{ }^{-}\right]$ionic liquid electrolyte showed a capacity of the order of $3,000 \mathrm{mAh} \mathrm{g}^{-1}$, with a small decrease in performance during 35 cycles [60].

Moreover, most of the research studies have shown that the consumption of cyclable Li due to side reactions within the cell is the main cause responsible for the capacity fade of LFPbased Li-ion cells. Striebel et al. [61, 62] tested the cycled graphite anode and LFP cathode of a cycled LFP/graphite cell. They found that both the electrodes well-maintained their specific capacity except the loss of lithium inventory. Dubarry et al. [63] attempted to identify the contributions of several factors to capacity loss by using an incremental capacity analysis. Again, lithium inventory loss is found to be the main cause of the capacity degradation of the LFP-based cell. Liu et al. [64, 65] investigated the discharge profiles using a differential analysis, and they confirmed that the loss of reversible $\mathrm{Li}$ is responsible for most of capacity fade. They also used external lithium source to replenish the cycled cathode which has lost $30 \%$ of its capacity after 2,730 cycles. Most of the lost capacity was recovered and the cell cycled for additional 1,500 cycles. We investigated the electrochemical cycling behavior of a LFP-based cell with different upper voltage limits, and the results indicated that lithium inventory loss is the most important factor leading to the capacity loss regardless of the charge voltage limit applied to the cell [66].

Interfacial stability with electrode is an essential factor to guarantee acceptable performance in the electrochemical devices. The interfacial stability between the electrolyte and the lithium electrode was investigated by monitoring the impedance response of a symmetrical Li/electrolyte/Li cell for a period of $542 \mathrm{~h}$.

Evolution of impedance spectra of the symmetrical Li|PE1|Li cell, kept under open circuit conditions, is shown as a function of the storage time (Fig. 10). The cell was tested immediately after its assembling without electrochemical charging/discharging. Spectra consist of a flat quasisemicircle followed by a short straight line at the lowfrequency region. It may be seen that the impedance considerably increases with storage time. Impedance measured immediately after cell assembling is ca. $8,200 \Omega \mathrm{cm}^{2}$, while during storage, it increases up to ca. $13,000 \Omega \mathrm{cm}^{2}$ after 542 h. (Fig. 10b). The interfacial resistance between the polymer electrolyte based on the modified silica (ESM5) membrane and the lithium electrode is also found to gradually increase from 2,000 to $3,400 \Omega \mathrm{cm}^{2}$ with the same storage time, as shown in Fig. 10a. Similar values were obtained with the addition of nanoSiO ${ }_{2}-\mathrm{P}$ (VDF-HFP) porous polymer electrolytes for Li-ion batteries [67]. As shown in Fig. 10a, the cell impedance mainly consists of a superimposed semicircle in the high-frequency to medium-frequency range which can be deconvoluted into two consecutive semicircles corresponding to the impedance of SEI layer formed on the surface of the electrodes $\left(R_{\mathrm{SEI}}\right)$ and that of the Faradic charge transfer resistance $\left(R_{\mathrm{ct}}\right)$, respectively $[68,69]$. It is noted that the total cell impedance increases from $1,950 \Omega$ after $10 \mathrm{~h}$ to $3,250 \Omega$ after $542 \mathrm{~h}$.

The increased reactivity of gel polymer electrolyte results in thicker surface film and higher interphasial resistance that is responsible for higher cell polarization, lower cell capacity, and quick capacity decay with cycling. Scrosati et al. have shown that this reactivity could be significantly reduced when intercalation electrode such as $\mathrm{Li}_{4} \mathrm{Ti}_{5} \mathrm{O}_{12}$ was used to replace lithium metal as the anode during battery fabrication [70]. In
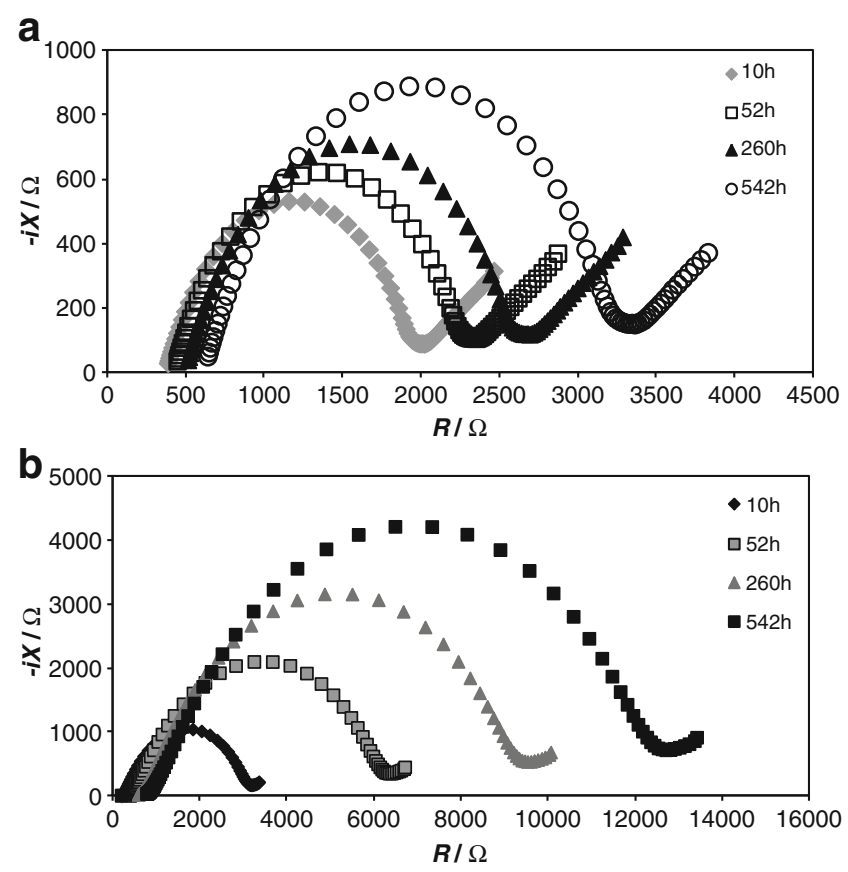

Fig. 10 Impedance evolution of the Li|electrolyte|Li system as a function of storage time: a) ESM5 b) EN - electrolyte without fillers 
the future, we will optimize the cell performance of lithiumion batteries using gel polymer electrolyte and dual intercalation electrodes.

The higher interfacial resistance for the polymer electrolyte based on direct composite membrane during the storage seems to be associated with the growth of a passivation layer on the lithium electrode surface and the degradation of the physical contact between the electrolyte and lithium electrode [13, 71]. As analyzed by SEM, the insulative silica particles are concentrated in the surface of membrane for direct composite sample, leading to an increase of resistance.

\section{Conclusions}

A new type of unmodified and modified filler for polymer gel electrolytes $\mathrm{SiO}_{2}-\mathrm{PAN} / \mathrm{TMS}$ has been described. The physical and electrochemical properties, such as porosity, specific surface area, particle size distributions, degree of modification of the silica diameter, uptake capacity, lithium-ion conductivity, and interfacial resistance, were investigated. New ceramic filler precipitated from emulsion system greatly facilitate solvent uptake by dry PAN/TMS with $\mathrm{LiPF}_{6}$ membranes, but only if they had been surface-modified. The state of the ceramic's surface chemistry seems to be an extremely important factor as far as its performance as a filler in gel electrolytes. The highest capacity and conductivity belong to the electrolyte which contains 5 wt.\% of 3 methacryloxypropyltrimethoxysilane (U-511), $350 \mathrm{mAh} \mathrm{g}^{-1}$. The charge/discharge efficiency of the cell: G|electrolyte|Li (C/5) was ca. $98 \%$ after 20 cycles.

The modified silica is found to be much better than the unmodified filler in lowering the interfacial resistance between electrolyte and lithium metal electrode, and presents stable charge-discharge behavior and little capacity loss of battery. Precipitation silica and additive to PAN/TMS is a promising method to polymer electrolyte for lithium batteries.

\section{Acknowledgments Support of grant 31-257/2013 DS-MK is gratefully acknowledged.}

Open Access This article is distributed under the terms of the Creative Commons Attribution License which permits any use, distribution, and reproduction in any medium, provided the original author(s) and the source are credited.

\section{References}

1. Katz HS, Milewski JV (1989) Handbook of fillers for plastics. Van Nostrand Reinhold, New York

2. Nielsen LE (1974) Mechanical properties of polymers and composites, vol 2. Marcel Dekker, New York

3. Rong MZ, Zhang MQ, Zheng YX, Zeng HM, Walter R, Friedrich K (2001) Polymer 42:167-183
4. Rong MZ, Zhang MQ, Zheng YX, Zeng HM, Friedrich K (2001) Polymer 42:3301-3304

5. Sombatsompop N, Wimolmala E, Markpin T (2007) J Appl Polym Sci 104:3396-3405

6. Sae-oui P, Sirisina C, Hatthapanit K (2007) Polym Lett 1:8-14

7. Suzuki N, Ito M, Ono S (2005) J Appl Polym Sci 95:74-81

8. Jesionowski T, Bula K, Janiszewski J, Jurga J (2003) Compos Interfac 10:225-242

9. Bula K, Jesionowski T, Krysztafkiewicz A, Janik J (2007) Colloid Polym Sci 285:1267-1273

10. Mathew G, Huh M-Y, Rhee JM, Lee M-H, Nah C (2004) Polym Adv Technol 15:400-408

11. Feuillade G, Perche P (1975) J Appl Electrochem 5:63-69

12. Nagatomo T, Ichikawa C, Omato O (1987) J Electrochem Soc 134: 305-308

13. Groce F, Gerace F, Dautzemberg G, Passerini S, Appetecchi GB, Scrosati B (1994) Electrochim Acta 39:2187-2194

14. Peramunage D, Pasquariello DM, Abraham KM (1995) J Electrochem Soc 142:1789-1798

15. Iijima T, Toyoguchi Y, Eda N (1985) Denki Kagaku 53:619-621

16. Tarascon J-M, Gozdz AS, Schmutz C, Shokoohi F, Warren PC (1996) Solid State Ionics 86-88:49-54

17. Gozdz A S, Schmutz C, Tarascon JM. US Patent No. 5296318 5: 296-318

18. Kumar B, Scanlon LG, Spry RJ (2001) J Power Sources 96:337-342

19. Croce F, Appetecchi GB, Persi L, Scrosati B (1998) Nature 394:456458

20. Croce F, Persi L, Scrosati B, Serrainoi-Fiory F, Plichta E, Hendrickson MA (2001) Electrochim Acta 46:2457-2461

21. Liu Y, Lee JY, Hong L (2004) J Power Sources 129:303-311

22. Świerczyński D, Zalewska A, Wieczorek W (2001) Chem Mater 13: $1560-1564$

23. Marcinek M, Bac A, Lipka P, Zalewska A, Zukowska G, Borkowska R, Wieczorek W (2000) J Phys Chem B 104:11088-11093

24. Caillon-Caravanier M, Claude-Montigny B, Lemordant D, Bosser G (2002) J Power Sources 107:125-132

25. Zhang S, Lee JY, Hong L (2004) J Power Sources 134:95-102

26. Yerian JA, Khan SA, Fedkiw PS (2004) J Power Sources 135:232 239

27. Choi E-S, Lee S-Y (2011) J Mater Chem 21:14747-14754

28. Cho TH, Sakai T, Tanase S, Kimura K (2007) Electrochem SolidState Lett 10:A159-A162

29. Zhang SS (2007) J Power Sources 164:351-364

30. Lee YM, Kim J-W, Choi N-S (2005) J Power Sources 139: 235-241

31. Hwang K, Kwon B, Hyun H (2011) J Membr Sci 378:111-116

32. Mauritz KA, Warren RM (1989) Macromolecules 22:1730-1734

33. Baradie B, Dodelet JP, Guay G (2000) J Electroanal Chem 489:101105

34. Apichatachutapan W, Moore RB, Mauritz KA (1996) J Appl Polym Sci 62:417-426

35. Shao PL, Mauritz KA, Moore RB (1995) Chem Mater 7:192-200

36. Costamagna P, Yang C, Bocarsly AB, Srinivasan S (2002) Electrochim Acta 47:1023-1033

37. Yang C, Srinivasan S, Aricň AS, Creti P, Baglio V, Antonucci V (2001) Electrochem Solid-State Lett 4A:31-34

38. Wang H, Holmberg BA, Huang L, Wang Z, Mitra A et al (2002) J Mater Chem 12:834-837

39. Suzhen R, Gongquan S, Chennan L, Zhenxing L, Zhimou W, Wie J, Xin Q, Xuefen Y (2006) J Membr Sci 282:450-455

40. Di Noto V, Boaretto N, Negro E, Pace G (2010) J Power Sources 195: 7734-7742

41. Wainright JS, Litt MH, Savinell RF (2003) High-temperature membranes. In: Vielstich W, Lamm A, Gasteiger HA (eds) Handbook of fuel cells: fundamentals technology and applications, vol 3. Wiley, Chichester, p 436 
42. Di Noto V, Negro E, Sanchez J-Y, Iojoiu C (2010) J Am Chem Soc 132:2183-2195

43. Thayumanasundaram S, Piga M, Lavina S, Negro E, Jeyapandian M, Ghassemzadeh L, Müller K, Di Noto V (2010) Electrochim Acta 55: $1355-1365$

44. Lee S-Y, Yasuda T, Watanabe M (2010) J Power Sources 195:59095914

45. Fernicola A, Panero S, Scrosati B, Tamada M, Ohno H (2007) Chem Phys Chem 8:1103-1107

46. Switzer EE, Olson TS, Datye AK, Atanassov P, Hibbs MR, Fujimoto C, Cornelius CJ (2010) Electrochim Acta 55:3404-3408

47. Di Noto V, Scrosati B (2011) Electrochim Acta 57:4-13

48. Jesionowski T (2009) Compos Interfac 16:115-129

49. Rong MZ, Zhang MQ, Ruan WH (2006) Mater Sci Technol 22:787796

50. Hong RY, Fu HP, Zhang YJ, Liu L, Wang J, Li HZ, Zheng Y (2007) J Appl Polym Sci 105:2176-2184

51. Yazdimamaghani M, Pourvala T, Motamedi E, Fathi B, Vashaee D, Tayebi L (2013) Materials 6:3727-3741

52. Chen Y, Wanf C, Chen J, Liu X, Tong Z (2009) J Polym Sci A Polym Chem 47:1354-1367

53. Zalewska A, Walkowiak M, Niedzicki L, Jesionowski T, Langwalda N (2010) Electrochim Acta 55:1308-1313

54. Galinski M, Lewandowski A, Stepniak I (2006) Electrochim Acta 51: $5567-5580$

55. Nakagawa H, Izuchi S, Kuwana K, Nukuda T, Aihara Y (2003) J Electrochem Soc 150:A695-A700

56. Ishikawa M, Sugimoto T, Kikuta M, Ishiko E, Kono M (2006) J Power Sources 162:658-662
57. Matsumoto H, Sakaebe H, Tatsumi K, Kikuta M, Ishiko E, Kono M (2006) J Power Sources 160:1308-1313

58. Saint J, Best AS, Hollenkamp AF, Kerr J, Shin JH, Doeff MM (2008) J Electrochem Soc 155:A172-A180

59. Sugimoto T, Atsumi Y, Kikuta M, Ishiko E, Kono M, Ishikawa M (2009) J Power Sources 189:802-805

60. Baranchugov V, Markevich E, Pollak E, Salitra G, Aurbach D (2007) Electrochem Commun 9:796-800

61. Striebel K, Guerfi A, Shim J, Armand M, Gauthier M (2003) J Power Sources 191-192:951-954

62. Shim J, Striebel K (2003) J Power Sources 119-121:955-958

63. Dubarry M, Svoboda V, Hwu R, Liaw BY (2006) Electrochem SolidState Lett 9(10):A454-A457

64. Liu P, Wang J, Hicks-Garner J, Sherman E, Soukiazian S, Verbrugge M, Tataria H, Musser J, Finamore P (2010) J Electrochem Soc 157(4):A499-A507

65. Wang J, Soukiazian S, Verbrugge M, Tataria H, Coates D, Hall D, Liu P (2011) J Power Sources 196:5966-5969

66. Zheng H, Chai L, Song X, Liu G, Battaglia V (2012) Electrochim Acta 62:256-262

67. He X, Shib Q, Zhou X, Wan C, Jiang C (2005) Electrochim Acta 51: 1069-1075

68. Chang YC, Jong JH, Fey GT (2000) J Electrochem Soc 147:20332038

69. MacFarlane DR, Meakin P, Sun J, Amini N, Forsyth M (1999) J Phys Chem B 103:4164-4170

70. Reale P, Fernicola A, Scrosati B (2009) J Power Sources 194:182-189

71. Appetecchi GB, Croce F, Scrosati B (1995) Electrochim Acta 40: 991-997 